\title{
WAVE HEIGHT DISTRIBUTIONS IN SHALLOW WATERS
}

\author{
Stephan Mai ${ }^{1}$, Jens Wilhelmi ${ }^{1}$ and Ulrich Barjenbruch ${ }^{1}$
}

\begin{abstract}
In shallow waters the wave height distribution significantly differs from Rayleigh distribution during extreme wind conditions. The EurOtop manual (Pullen et al. 2007) recommends the use of a composite Rayleigh-Weibull distribution proposed by Battjes and Groenendijk (2000) in order to describe the wave statistics in shallow waters. A test of this recommendation by using wave measurements with continuously operated radar level gauges at three different sites at the German North Sea coast for comparison revealed the necessity for a change in the parameterization given in the EurOtop manual.
\end{abstract}

Keywords: wave height statistics, radar measurement, shallow water, Battjes-Groenendijk / Rayleigh distribution

\section{INTRODUCTION}

The design of offshore or coastal structures, like offshore wind farms or breakwaters, is generally taking reference to the maximum wave height to be expected during storms. In order to derive this design-wave-height, knowledge of the local wave-height distribution is of major importance. In deep water, the wave-height distribution is of Rayleigh type (Longuet-Higgins, 1952). Although in shallow water the distribution significantly differs from the Rayleigh type (Klopman and Stive, 1989, Nelson, 1994, Burchardt et al., 1996, Battjes and Groenendijk, 2000), the Rayleigh distribution is still widely used in designing structures in shallow waters, what leads to oversized and thus excessively costly structures. Therefore, designers should consider the restrictions of the Rayleigh distribution (Forristall, 2008), especially because an increasing number of offshore wind farms or LNG terminals will be built in shallow waters in the near future.

Battjes and Groenendijk (2000) proposed a composite Rayleigh-Weibull distribution, i.e. Rayleigh distribution for wave heights below a certain transition wave-height and Weibull distribution there above, in order to take the effect of water depth on the wave-height distribution into account. This approach is recommended in the EurOtop manual (Pullen et al. 2008).

\section{DESCRIPTION OF ON-SITE MEASUREMENTS}

In order to check the results of Battjes and Groenendijk (2000), which were obtained from laboratory data, long-term in-situ wave measurements were made at different locations in the German part of the North-Sea (Barjenbruch and Wilhelmi, 2008, Mai, 2008), see Fig. 1. The water depth varies from $8 \mathrm{~m}$ (gauge Borkum) to $11 \mathrm{~m}$ at the lighthouse "Alte Weser" to $29 \mathrm{~m}$ at the research station FINO 1.

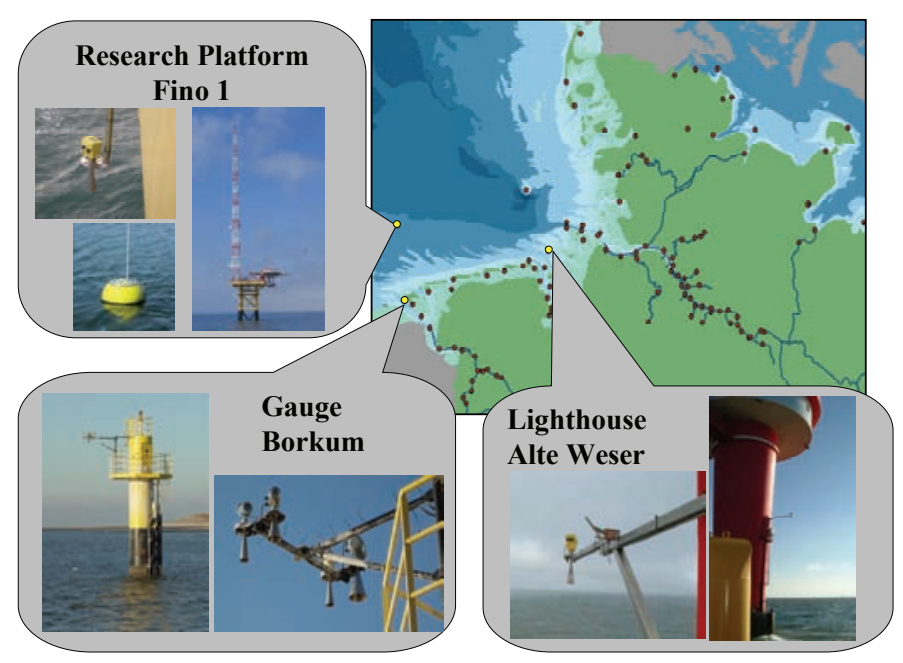

Figure 1. Locations of wave sensors at the German North Sea coast (highlighted in yellow) and photos of the instrumentation.

1 Dept. M1 "Hydrometry and Hydrological Survey", Federal Institute for Hydrology, Am Mainzer Tor 1, 56076 Koblenz, Germany 
The waves were measured by radar wave gauges (Barjenbruch and Wilhelmi, 2008, Barjenbruch et al. 2002). In addition to that a waverider buoy was installed at the research platform FINO 1. The comparison of significant wave heights shows a good agreement of both measuring systems (see Fig. 2).

The operation of the wave sensors is ongoing since August 2002 at the gauge Borkum, since September 2006 at the lighthouse "Alte Weser" and since February 2008 at the research platform FINO 1. The sampling frequency of the radar sensors is approximately $2 \mathrm{~Hz}$. A time-series of water level elevations and the spectral density is given in Fig. 3 for a severe storm surge in 2006. The measurements were analyzed in time domain applying the zero-downcrossing method (IAHR Working Group on Wave Generation and Analysis 1989). The distributions of wave height and period are derived for time intervals of one hour. An example is given in Fig. 4. For the $1 \mathrm{~h}$ intervals characteristic wave parameters, e.g. significant and maximum wave height, are calculated (see Fig. 5). Only 1 hour intervals fulfilling the shallow water condition $\mathrm{H}_{\max } / \mathrm{d}>0.35$ were selected for further analysis of the wave height distribution (see Fig. 5).

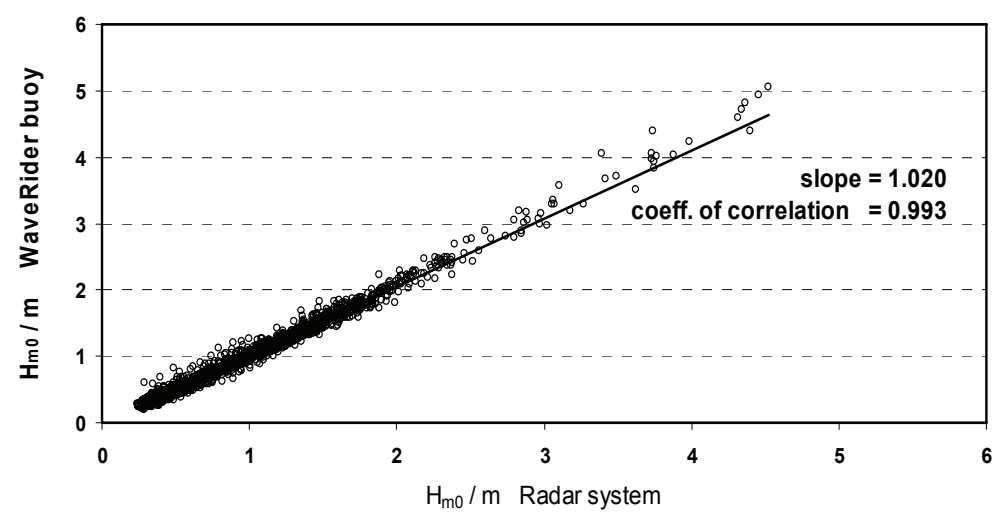

Figure 2. Correlation between significant wave heights measured by radar systems and waverider buoys.
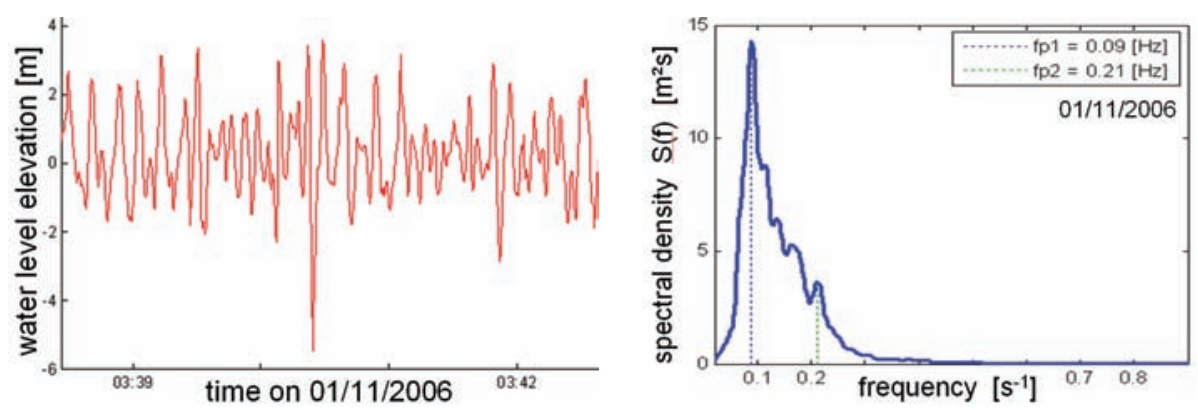

Figure 3. Time-series (left) and spectral density (right) of the water level elevation at the lighthouse "Alte Weser" during a severe storm surge on 01/11/2006.
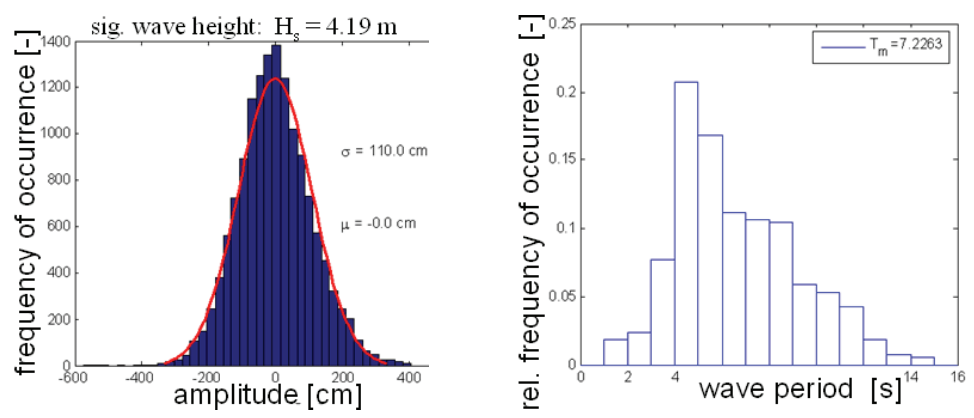

Figure 4. Distribution of wave amplitudes (left) and wave periods (right) at the lighthouse "Alte Weser" during a severe storm surge on 01/11/2006. 

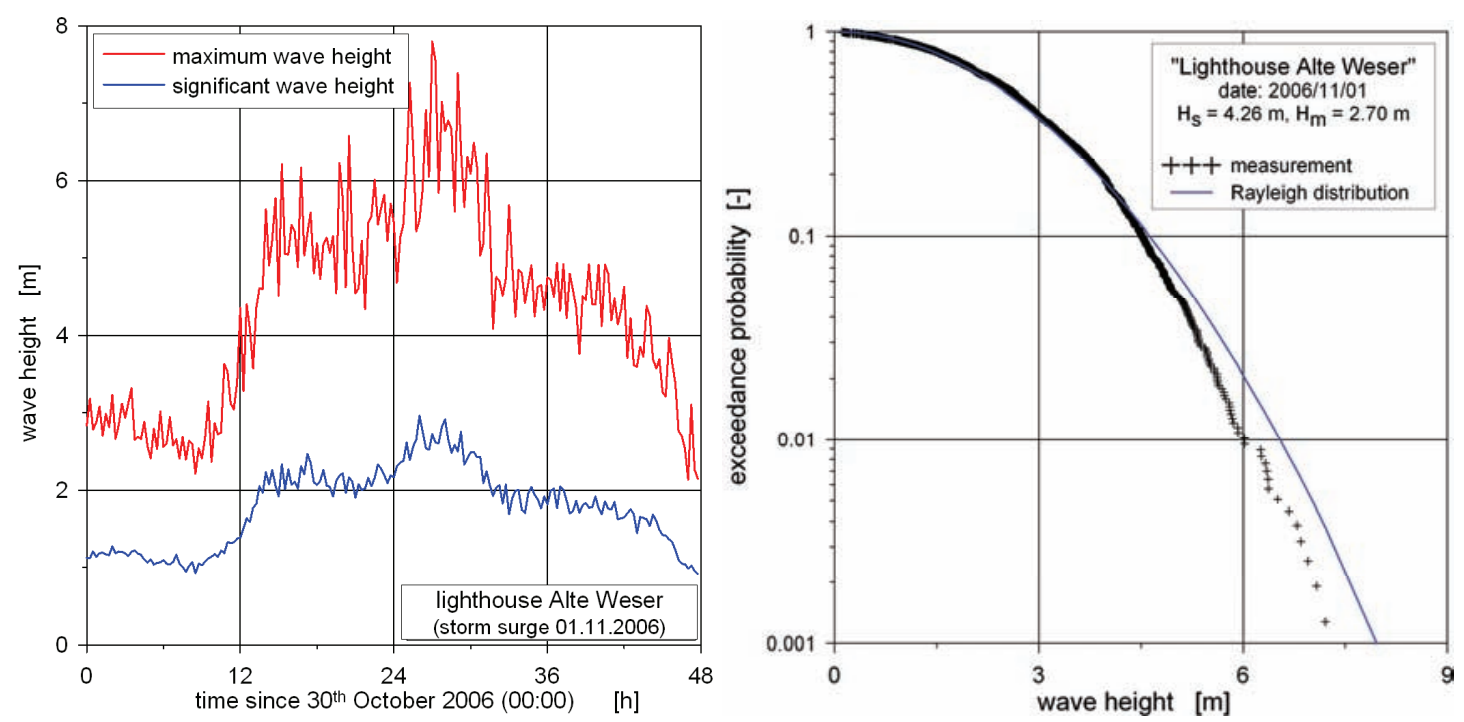

Figure 5. Time-series of significant and maximum wave height (left) and wave height statistics (right) at the lighthouse "Alte Weser" during a severe storm surge on 30/10/2006 and 01/11/2006.

\section{MATHEMATICS OF WAVE HEIGHT DISTRIBUTIONS}

As given in Fig. 5 the wave height statistics in shallow waters significantly differs from the Rayleigh distribution. To account for this Nelson (1994) proposed to use the following relation between maximum wave height $\left(\mathrm{H}_{\max }\right)$ and water depth $(\mathrm{d})$ :

$$
\mathrm{H}_{\max } \leq 0,55 \mathrm{~d}
$$

Stive (1986) addressed the height of the 1 in 100 or the 1 in 1000 wave by

$$
\begin{aligned}
& \mathrm{H}_{1.0 \%}=\mathrm{H}_{\mathrm{m} 0} \cdot(0,5 \cdot \ln (100))^{0,5} \cdot\left(1+\mathrm{H}_{\mathrm{m} 0} / \mathrm{d}\right)^{-0,33} \\
& \mathrm{H}_{0.1 \%}=\mathrm{H}_{\mathrm{m} 0} \cdot(0,5 \cdot \ln (1000))^{0,5} \cdot\left(1+\mathrm{H}_{\mathrm{m} 0} / \mathrm{d}\right)^{-0,50}
\end{aligned}
$$

with the significant wave height $\left(\mathrm{H}_{\mathrm{m} 0}\right)$.

Battjes and Groenendijk (2000) suggested the use of a composite distribution of Rayleigh type for low wave heights and of Weibull type for high wave heights

$$
\mathrm{P}(\mathrm{H})=\left\{\begin{array}{cl}
\exp \left(-\frac{\mathrm{H}^{2}}{\mathrm{H}_{1}^{2}}\right) & \mathrm{H} \leq \mathrm{H}_{\mathrm{tr}} \\
\exp \left(-\frac{\mathrm{H}^{\mathrm{k}}}{\mathrm{H}_{\mathrm{tr}}^{\mathrm{k}-2} \cdot \mathrm{H}_{1}^{2}}\right) & \mathrm{H} \geq \mathrm{H}_{\mathrm{tr}}
\end{array}\right.
$$

with the transition wave height $\left(\mathrm{H}_{\mathrm{tr}}\right)$, the parameter of the Rayleigh distribution $\left(\mathrm{H}_{1}\right)$ and the Weibull parameter (k). The transition wave height is defined as a function of water depth (d) and sea bed slope $(\alpha)$

$$
\mathrm{H}_{\mathrm{tr}}=\left(\beta_{\mathrm{tr}, 1}+\beta_{\mathrm{tr}, 2} \tan \alpha\right) \cdot \mathrm{d}
$$

with the parameters $\beta_{\mathrm{tr}, 1}$ and $\beta_{\mathrm{tr}, 2}$. On the basis of laboratory experiments Battjes and Groenendijk (2000) proposed the following parameter set: $\mathrm{k}=3.6, \beta_{\mathrm{tr}, 1}=0.35, \beta_{\mathrm{tr}, 2}=5.8$.

\section{RESULTS}

For each of the three given sites and every wave event fulfilling the above given shallow water condition a comparison of the wave height distribution, derived from measurements, with the empirical distributions - Rayleigh distribution, composite Rayleigh-Weibull distribution with the parameter set of Battjes and Groenendijk (2000) and composite Rayleigh-Weibull distribution with optimized parameter set - was carried out. 
Fig. 6 shows the wave height distribution at the lighthouse "Alte Weser" during the storm surge on 01/11/2006. The wave height distribution calculated with Battjes-Groenendijk approach using the original parameter set of Battjes and Groenendijk (2000) underestimates the probability of high waves. This problem is not only related to the choice of the transition wave height (see Fig. 6, left). Only an adjustment of transition wave height and Weibull parameter leads to an acceptable fit between measured distribution and composite Rayleigh-Weibull distribution (Fig. 6, right). The optimal parameter set of the composite Rayleigh-Weibull distribution was calculated by least-squares-fitting of $\log (\mathrm{P})$. For the storm surge of $01 / 11 / 2006$ - the most extreme wave condition while operating the radar sensor at the lighthouse "Alte Weser" - the following parameter set is optimal: $\mathrm{k}=2.42$ and $\beta_{\mathrm{tr}, 1}=0.30$ (with $\tan \alpha=0$ ). At the site of the lighthouse "Alte Weser" the parameter set varies in the following range (Fig. 7):

$$
2.17<\mathrm{k}_{\text {Alte Weser }}<2.46
$$

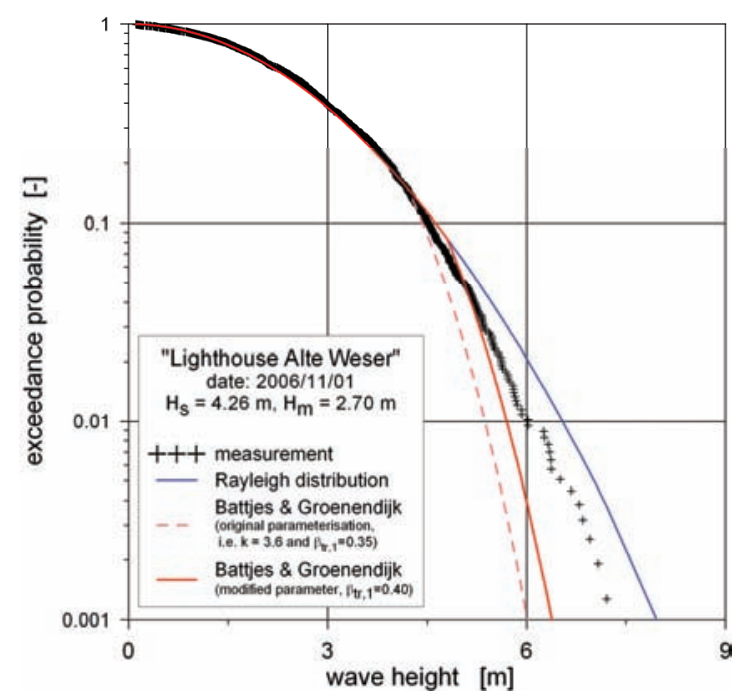

$0.20>\beta_{\text {tr }, 1, \text { Alte Weser }}>0.40$

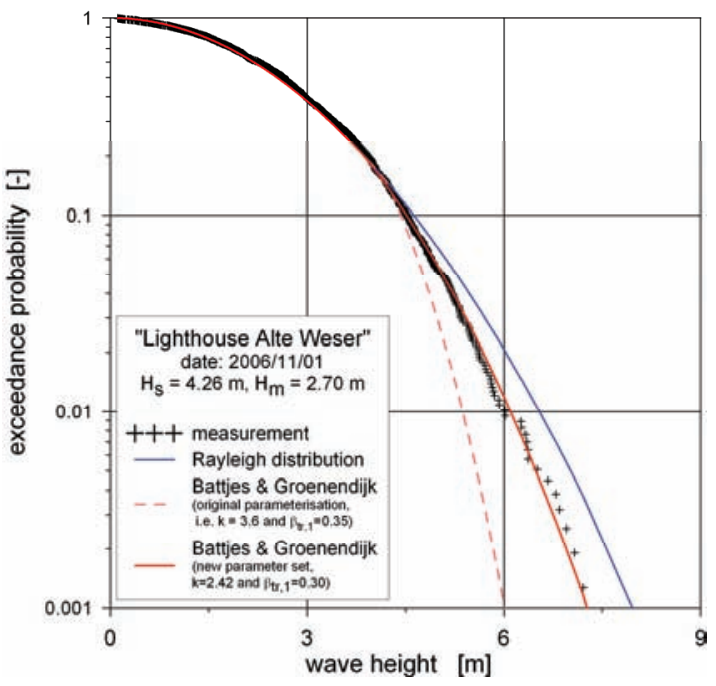

Figure 6. Comparison of measured wave height distribution with different empirical distributions at the lighthouse "Alte Weser" during a severe storm surge on 01/11/2006.
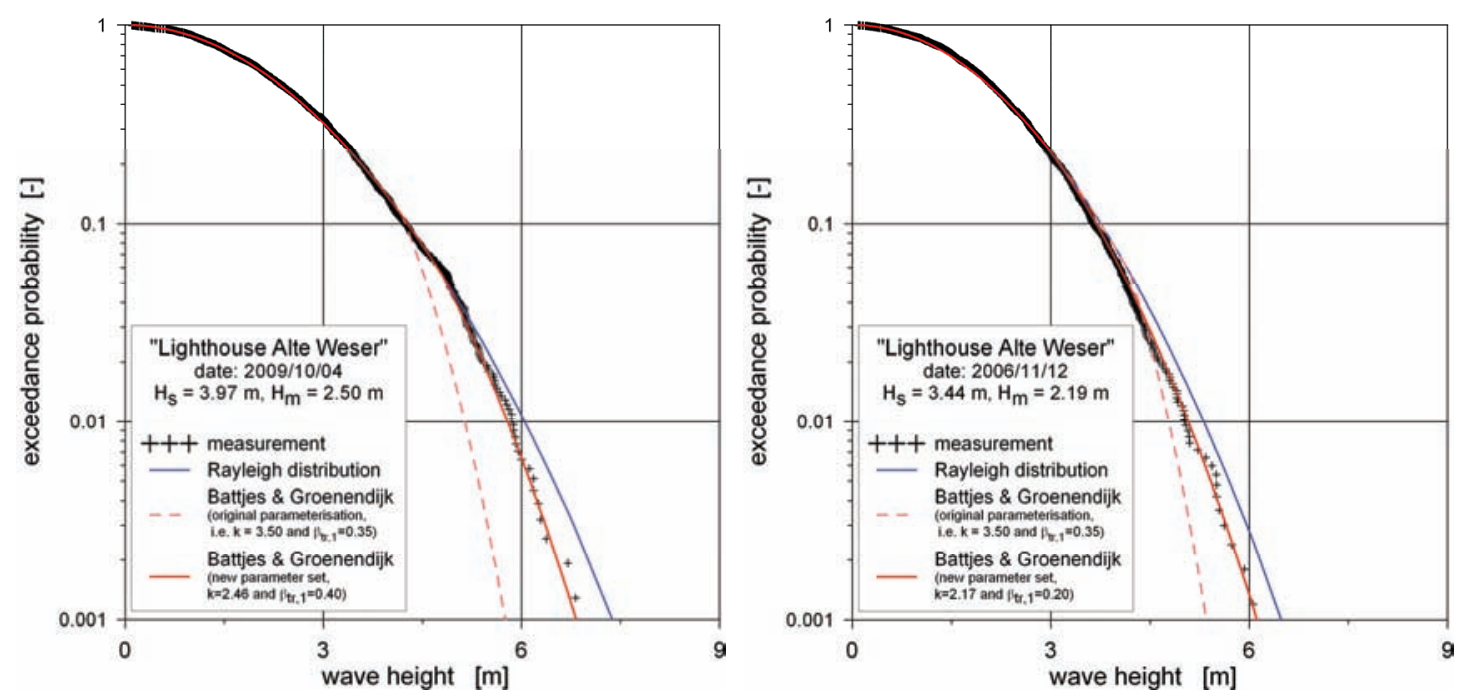

Figure 7. Wave height distributions at the lighthouse "Alte Weser" exemplifying the most extreme parameter sets of the composite Rayleigh-Weibull distribution.

At the research platform FINO 1 only few wave events fulfilled the above given shallow water condition. Fig. 8 gives examples of the wave height distributions during two storm events. Fig. 8 also includes the original and the modified composite Rayleigh-Weibull distribution. The modified 
parameter sets for the different wave events significantly differ from those presented by Battjes and Groenendijk (2000). The spread of the parameter sets is very little. Best agreement of measurement and mathematical formulation is achieved using the following parameter set:
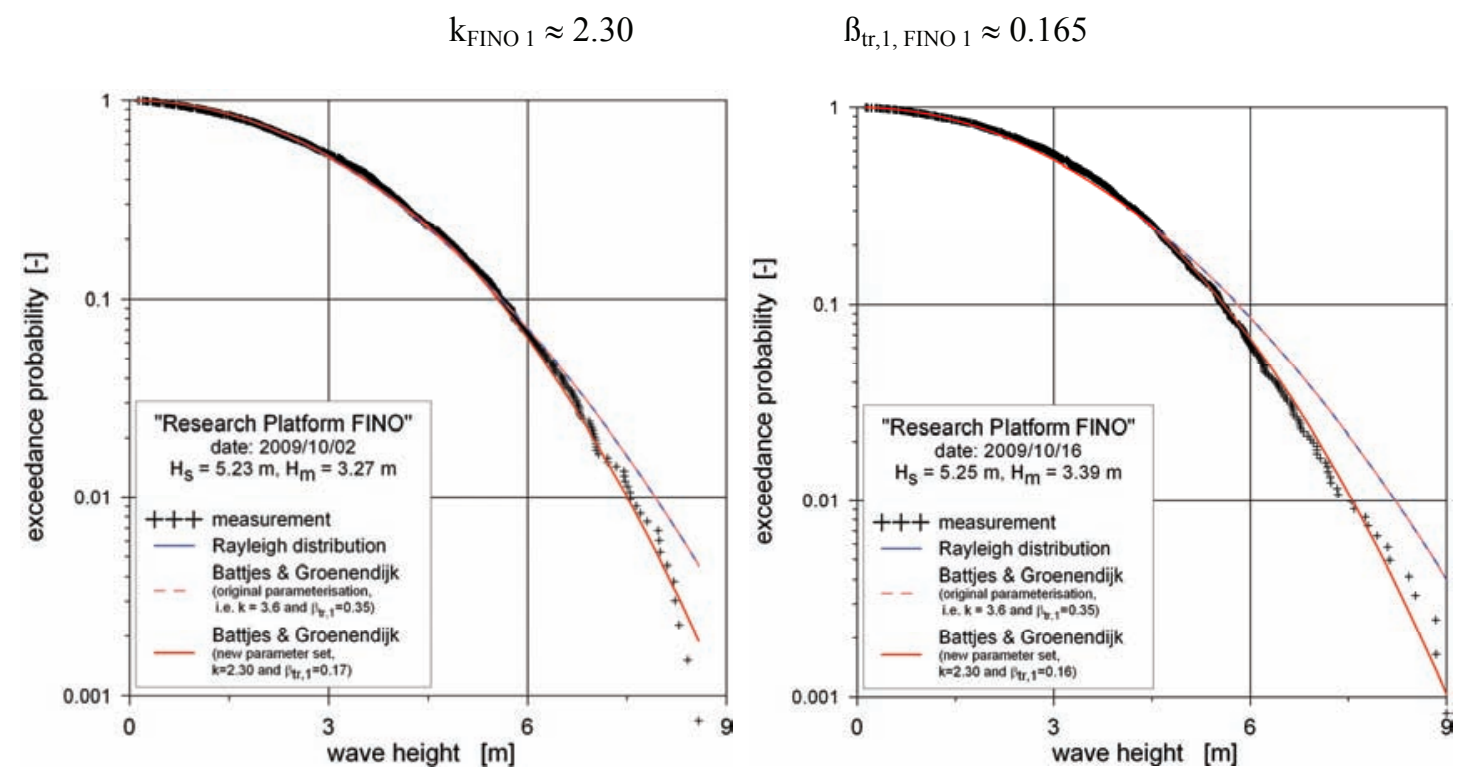

Figure 8. Wave height distributions at the research platform FINO 1 during storm surges on 02/10/2009 (left) and 16/10/2006 (right).
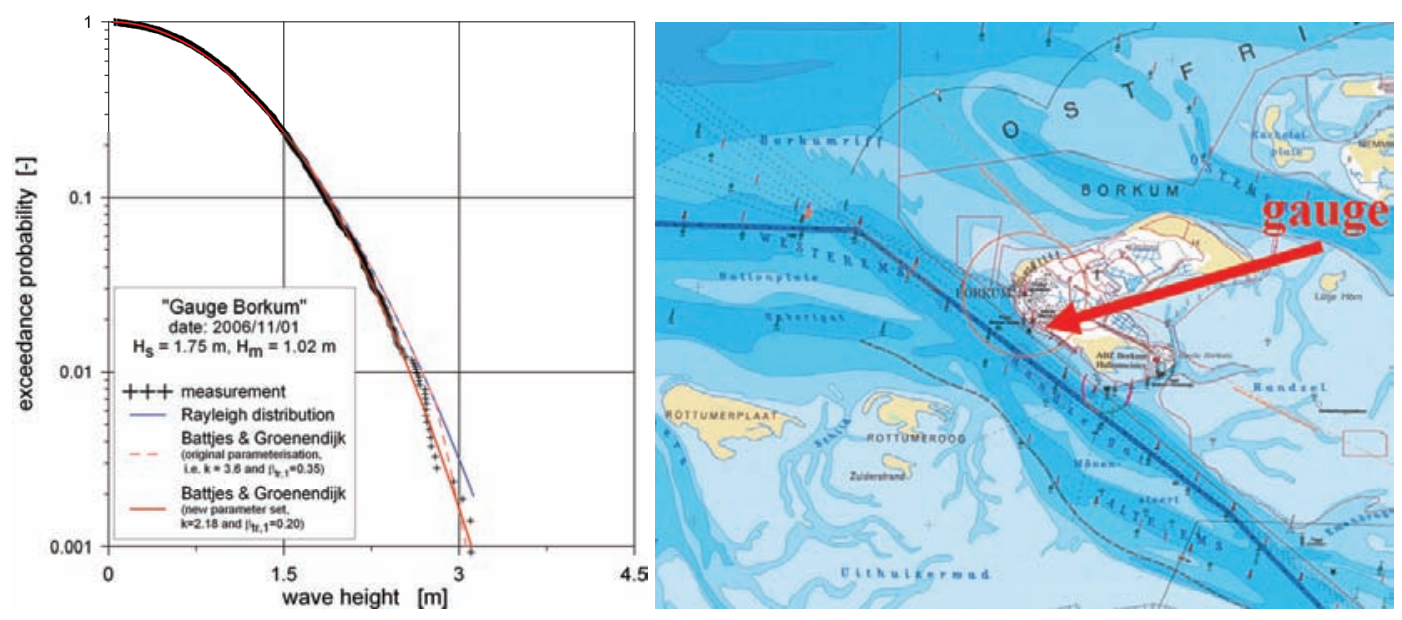

Figure 9. Wave height distribution at the gauge Borkum (left) and location of the measuring site with neighboring shallow water areas west and north of the island Borkum (right).

Although wave data were gathered for about 8 years at the gauge "Borkum-Südstrand", the maximum ratio of significant wave height and water depth is comparably low. It amounts to 0.22 . This relates to the fact that incoming waves from the North-Sea start to break over the large shallow water areas west and north of the measuring site (Fig. 9, right). Best agreement of measurement and mathematical formulation is achieved using the following parameter set of the composite RayleighWeibull distribution (Fig. 9):

$$
\mathrm{k}_{\text {Borkum }} \approx 2.18 \quad \beta_{\text {tr }, 1, \text { Borkum }} \approx 0.20
$$




\section{CONCLUSIONS}

The wave height distribution in shallow waters of the North-Sea significantly differs from a Rayleigh distribution. Composite Rayleigh-Weibull distributions as proposed by Battjes and Groenendijk (2000) fit field data better. However the parameter set given by Battjes and Groenendijk (2000), which is also included in the EurOtop manual (Pullen et al. 2007), needs to be checked when used in design. For three locations at the German North Sea Coast it is found that the Weibull parameter $\mathrm{k}$ and the transition parameter $\beta_{\mathrm{tr}, 1}$ is lower (than proposed by Battjes-Groenendijk). The Weibull parameter $\mathrm{k}$ amounts on average to 2.31 . The transition parameter $\beta_{\mathrm{tr}, 1}$ equals on average 0.23 .

\section{ACKNOWLEDGMENTS}

This study is part of the research project "Climate Change and Waterways (KLIWAS)" (further information is given under www.kliwas.de). The project is funded by the German Federal Ministry of Transport, Building and Urban Affairs, gratefully acknowledged by the authors.

\section{REFERENCES}

Barjenbruch, U., S. Mai, N. Ohle, and U. Mertinatis. 2002. Monitoring Water Level, Waves and Ice with Radar Gauges, Proceedings of the Hydro 2002 Conference, DHyG, 328-337.

Barjenbruch, U., and J. Wilhelmi. 2008. Application of radar gauges to measure the water level and the sea state, Proceedings of $31^{\text {st }}$ International Conference on Coastal Engineering, ASCE, 687-695.

Battjes, J.A., and H.W. Groenendijk. 2000. Wave height distributions on shallow foreshores, Coastal Engineering, 40, 161-182.

Burcharth, H.F., P. Frigaard, J. Uzcanga, J.M. Berenguer, B.G. Madrigal, and J. Villanueva. 1996. Design of the Ciervana breakwater, Bilbao, Advances in coastal structures and breakwaters, Thomas Telford, London, 26-43.

Forristall, G. 2008. Offshore LNG terminal designs must overcome complications of shallow water, Oil \& Gas Journal, 106(43).

IAHR Working Group on Wave Generation and Analysis. 1989. List of Sea-State Parameters, Journal of Waterway, Port, Coastal and Ocean Engineering, 115(6), pp. 793-80

Klopman, G., and M.J.F. Stive. 1989. Extreme waves and wave loading in shallow water, Proceedings of E\&P Forum Workshop: Wave and current kinematics and loading, Paris, Oct. 25-26.

Longuet-Higgins, M. S. 1952. On the Statistical Distribution of the Heights of Sea Waves. Journal of Marine Research, 11(3), 245-266.

Mai, S. 2008. Statistics of Waves in the Estuaries of the Rivers Ems and Weser - Measurement vs. Numerical Wave Model, Proceedings of the $7^{\text {th }}$ Int. Conf. on Coastal and Port Engineering in Developing Countries COPEDEC, CD-ROM.

Nelson, R.C. 1994. Depth limited design wave heights in very flat regions, Coastal Engineering, 23, 43-59.

Pullen, T., N.W.H. Allsop, T. Bruce, A. Kortenhaus, H. Schüttrumpf, and J.W. van der Meer. 2007. EurOtop - Wave Overtopping of Sea Defences and Related Structures: Assessment Manual, Die Küste, 73, 193 pp. (online: http://www.overtopping-manual.com/eurotop.pdf) 